\title{
Estimating ancestral proportions in a multi-ethnic US sample: implications for studies of admixed populations
}

\author{
Orna Levran ${ }^{1 *}$, Olaoluwakitan Awolesi ${ }^{1}$, Pei-Hong Shen ${ }^{2}$, Miriam Adelson ${ }^{3}$ and Mary Jeanne Kreek
}

\begin{abstract}
This study was designed to determine the ancestral composition of a multi-ethnic sample collected for studies of drug addictions in New York City and Las Vegas, and to examine the reliability of self-identified ethnicity and three-generation family history data. Ancestry biographical scores for seven clusters corresponding to world major geographical regions were obtained using STRUCTURE, based on genotypes of 168 ancestry informative markers (AIMs), for a sample of 1,291 African Americans (AA), European Americans (EA), and Hispanic Americans (HA) along with data from 1,051 HGDP-CEPH 'diversity panel' as a reference. Self-identified ethnicity and family history data, obtained in an interview, were accurate in identifying the individual major ancestry in the AA and the EA samples (approximately 99\% and 95\%, respectively) but were not useful for the HA sample and could not predict the extent of admixture in any group. The mean proportions of the combined clusters corresponding to European and Middle Eastern populations in the AA sample, revealed by AIMs analysis, were 0.13 . The HA subjects, predominantly Puerto Ricans, showed a highly variable hybrid contribution pattern of clusters corresponding to Europe (0.27), Middle East (0.27), Africa (0.20), and Central Asia (0.14). The effect of admixture on allele frequencies is demonstrated for two single-nucleotide polymorphisms (118A > G, $17 \mathrm{C}>\mathrm{T})$ of the mu opioid receptor gene (OPRM1). This study reiterates the importance of AIMs in defining ancestry, especially in admixed populations.
\end{abstract}

Keywords: Ancestry informative markers, Hispanics, African Americans, Family history, Ancestry, Admixture

\section{Introduction}

The well-established genetic differences between ancestral populations may have an effect on disease prevalence and outcomes, as well as on drug response [1]. The presence of subgroups that differ in allele frequencies is relevant to public health and has numerous clinical implications. Analysis of population structure using a clustering algorithm can distinguish between populations based on DNA polymorphisms [1]. Admixture occurs when a new hybrid population is formed from formerly isolated populations [2]. Estimating the proportions of different ancestries in admixed populations is especially important in casecontrol association studies, since spurious associations may occur due to population substructure $[3,4]$. To avoid spurious associations, researchers can adjust the regression

\footnotetext{
* Correspondence: levrano@rockefeller.edu

${ }^{1}$ The Laboratory of the Biology of Addictive Diseases, The Rockefeller University, New York NY10065, USA

Full list of author information is available at the end of the article
}

model in an association study for individual admixture by estimating individual ancestry with a set of ancestry informative markers (AIMs) that have high allele frequency differences between continental groups.

African and Hispanic Americans constitute a large part of the US population (approximately 12\% each). The majority of the African American (AA) population is a recently admixed population (average of approximately six generations, $>200$ years ago) generated primarily by forced migration from Africa and a diverse range of admixture with European Americans (EA) and Native Americans (NA).

The term Hispanics/Latinos refers to a diverse population of Latin American descent. The Hispanic/Latino complex genetic structure reflects over five centuries of historical confluence of three major parental populations: Native American, European (primarily from the Iberian Peninsula and Southern Europe), and West African populations, with very large variations in ancestry proportions 
that is a result of country-specific migration history. Several studies have reported the admixture of this population [e.g., 5-14]. The Hispanic subgroups in the USA were shown to differ in the prevalence of several diseases compared with African and European Americans. Admixture analysis may show whether genetics explains these differences and may allow discriminating between socio-demographic and genetic contribution.

This study was designed to determine the ancestry proportions of a large multi-ethnic sample, recruited for studies of drug addiction in the USA, with a set of 168 AIMs and to examine the concordance of self-reported ethnicities and family history with AIMs data.

\section{Materials and methods \\ Sample}

The sample of 1,291 subjects is part of a larger cohort that was recruited for genetic study of drug addiction in the Laboratory of the Biology of Addictive Diseases at The Rockefeller University, New York. This set included only subjects who self-reported to be AA, EA, or Hispanic American (HA), which are the major groups in our cohort. Subjects were recruited at The Rockefeller University Hospital, The Weill Medical College of Cornell University, New York, The Manhattan Campus of the VA NY Harbor Health Care System, and the Dr. Miriam and Sheldon G. Adelson Clinic for Drug Abuse Treatment and Research, Las Vegas. They included former opiate addicts in methadone maintenance treatment $(n=726)$, cocaine and/or alcohol addicts $(n=143)$, and healthy volunteers $(n=422)$. A subset of this sample (e.g., EA and AA opiate addicts and healthy volunteers) was included in our previously reported case-control association studies $[15,16]$.

Subjects completed a three-generation family history questionnaire developed in our laboratory as part of their ascertainment interview. The family history questionnaire includes questions on (1) place of birth (i.e., city, state, country, and region); (2) self-identified race, ethnicity, or cultural group; and (3) nationality. Each question was answered for self, parents, grandparents, and great-grandparents, when known. The questionnaire was filled in by an experienced clinician interviewer. No pre-set list of categories was provided. Responses were assigned into nine categories: African, AA, EA, HA, Asian, Caribbean African, NA, Other/ Mixed, and Unknown. Ambiguous responses were assigned by the authors based on geographical regions. All subjects signed an informed consent for genetic studies with a $99.7 \%$ consent rate [17]. The institutional review boards of The Rockefeller University, VA NY, and Cornell University approved the study. The Rockefeller University IRB also reviews the Adelson Clinic, Las Vegas.

\section{DNA preparation and genotyping}

DNA was extracted from blood using the standard salting-out method. Two hundred and fifty to five hundred ng DNA was used for genotyping, as described [16]. Genotyping of AIMs and OPRM1 single-nucleotide polymorphisms (SNPs) was performed on a 1,536-plex GoldenGate $^{\text {Tx }}$ Custom Panel (Illumina, San Diego, CA, USA) [18]. Genotyping was performed at The Rockefeller University Genomics Resource Center according to the manufacturer's protocol (Illumina). Analysis was performed using BeadStudio genotyping software (Illumina). Genotype data were filtered based on SNP call rates (>99.5\%) and cluster separation, and 18 AIMs were excluded from the analysis because of poor cluster separation (Additional file 1: Table S1). Random samples (approximately 10\%) were genotyped in duplicate with high reproducibility rate (99.9\%).

\section{Determination of individual ancestry by AIMs}

The set of 186 unlinked AIMs was selected based on differences in allele frequency by at least $70 \%$ and 10 fold between at least two continental populations (from among European, African, and Asian populations of the HapMap project) (Additional file 1: Table S1) [19]. Genotypes of 168 AIMs with adequate quality were analyzed using STRUCTURE v.2.2 software [20] to obtain individual ancestry proportions (ancestry biographical score). Analysis was also performed for a known set of 1,051 subjects representing 51 worldwide populations (the Cell Line Panel of the Human Genome Diversity Project (HGDP)/Centre d'Etude du Polymorphisme Humain (CEPH)) [21].

The number of clusters $(K)$ was defined by running the data with different $K$ values and computing the probability of $K=n$ in the HGDP sample. The seven-factor solution was optimal and closely replicated the sevenfactor solution found for the same 51 reference populations that matched major geographical regions $[1,22]$.

In the current analysis, the entire sample was analyzed simultaneously with the reference set in an 'anchored' approach that was shown to yield a stable factor structure interpretable in the context of worldwide genetic diversity [22-24]. An ancestry biographical score for seven clusters corresponding to geographical regions: Africa, Europe, Middle East, Central Asia, Far East Asia, Oceania (islands of the tropical Pacific Ocean), and America, was estimated for each individual, with reference to the 1,051 individual panel, and sum to 1 [22].

\section{Results}

A set of 1,291 subjects was selected for this study based on self-report ethnicity. This set is part of a larger cohort that was recruited for genetic study of drug addiction from New York City and Las Vegas. The subjects belong 
to the following self-reported groups: AA $(n=435)$, EA $(n=563)$, and HA $(n=293)$. Ancestry biographical scores for seven clusters $(K)$ were obtained for each subject using STRUCTURE analysis of 168 AIMs. The analysis was performed for each sample along with 1,051 HGDP samples as a reference (see the 'Materials and methods' section). Based on the HGDP sample, the seven factors correspond to the geographical regions of Africa, Europe, Middle East, Central Asia, Far East Asia, Oceania, and America, and they are named by the geographical regions hereafter, for simplicity. Figure 1a shows the relative ancestry contributions for each subject in each of the three groups. There is a very small contribution of clusters corresponding to Oceania and Far East Asia in this sample.

\section{African Americans}

Complete or almost complete ( $>10 / 14$ possible answers) three-generation family history was available for 296 subjects (68\%). Partial information was available for 87 subjects (20\%), and no family data were available for 52 subjects including 3 adopted subjects (12\%). Based on this data, the AA group can be divided into the following subgroups: AA for at least two generations with no report of another ancestry (41\%), AA with some Caribbean ancestry, African Caribbean, AA with some Native American ancestry, AA with some European ancestry, mixed ancestry, new immigrants from Africa, and unknown ancestry (Table 1).

Based on AIMs analysis, the major ancestry contribution for the majority (96\%) of the self-identified AA subjects is African, as is shown in Figure 1a. The second major contribution (0.26-0.40) is from Europe, Middle East, or Central Asia. The mean proportions of each of the major factors in the AA sample are shown in Table 1. The mean African contribution for the subgroups that were divided based on family history data was 0.80 for the subgroups of African Americans, African Caribbeans, some Caribbean ancestry, and some Native American ancestry. AIMs analysis detected a lower mean African contribution (0.70) in the sample that reported some European ancestry or mixed ancestry and a higher mean African contribution (0.94) in new immigrants from Africa, as expected, validating the sensitivity of this set of AIMs. Notably, there was a very small Native American contribution in all subgroups including those $(n=59)$ that reported some Native American ancestry.

Comparison between self-identification and AIMs data revealed 17 subjects for whom the contribution of the African factor was less than $50 \%$. There were 13 subjects (3\%) with an African contribution in the 0.25-0.5 range for which the other major contributing factor was European, Middle East, or Central Asia. There were four subjects $(0.9 \%)$ with a $<0.25$ African contribution, but none of them had family history data.

\section{Hispanic Americans}

Complete or almost complete three-generation family history was available for 202 subjects (71\%). Partial information was available for 53 subjects (18\%), and no family data were available for 32 subjects (11\%) including 1 adopted subject. Based on the three-generation family history data, the self-identified HA subjects can be divided to the following subgroups: Puerto Ricans (62\%), mixed or other Caribbean Islands, Latin Americans, Caribbean/Latin Americans, Puerto Ricans with European ancestry, and no data (Table 1).

Based on AIMs analysis, the distribution of individual admixture estimates in the HA sample show a wide range of ancestry proportions (Figure 1a). Of the 293 self-reported HA, 150 subjects (51\%) have a hybrid pattern of five ancestries (all with frequency <0.5), 52 subjects (18\%) have major European ancestry, 53 (18\%) subjects have a major Middle Eastern contribution, 22 subjects (8\%) have a major African ancestry contribution, 13 subjects (4\%) have a major Central Asian contribution, and 3 subjects (1\%) have a major Native American contribution (Figure 1b). The mean proportions of each of the five major clusters are listed in Table 1 . It is clear that the reported family history does not reflect the complex ancestry contribution indicated by analysis of AIMs. Although the mean contributions from Far East Asia and Oceania were low $(<0.02), 33$ subjects have a $>0.05$ contribution from Oceania and 24 subjects show a $>0.05$ contribution from Far East Asia. There is a higher contribution of Native American in the Latin American subgroup (0.19) and the mixed Caribbean/ Latin American subgroup (0.13) compared to other subgroups supporting the sensitivity of this set of AIMs.

\section{European Americans}

AIMs analysis of the 563 self-reported European Americans showed that the major ancestry contribution was as follows (Figure 1a): 494 subjects (88\%) have major European ancestry (>0.50), 33 (6\%) subjects have a major Middle Eastern contribution, 12 (2\%) subjects have a major Central Asian contribution, $4(<1 \%)$ subjects have a major African contribution, 18 (3\%) subjects have mixed contributions from Europe, Middle East, and Central Asia, and 2 subjects $(<1 \%)$ show mixed contributions from Europe, Middle East, and Native America. The mean proportions of the major factors are shown in Table 1.

The comparison between family ancestry and AIMs in this group is beyond the scope of this study, as the specific AIMs were designed for continental populations and are of limited use in detecting substructure in 


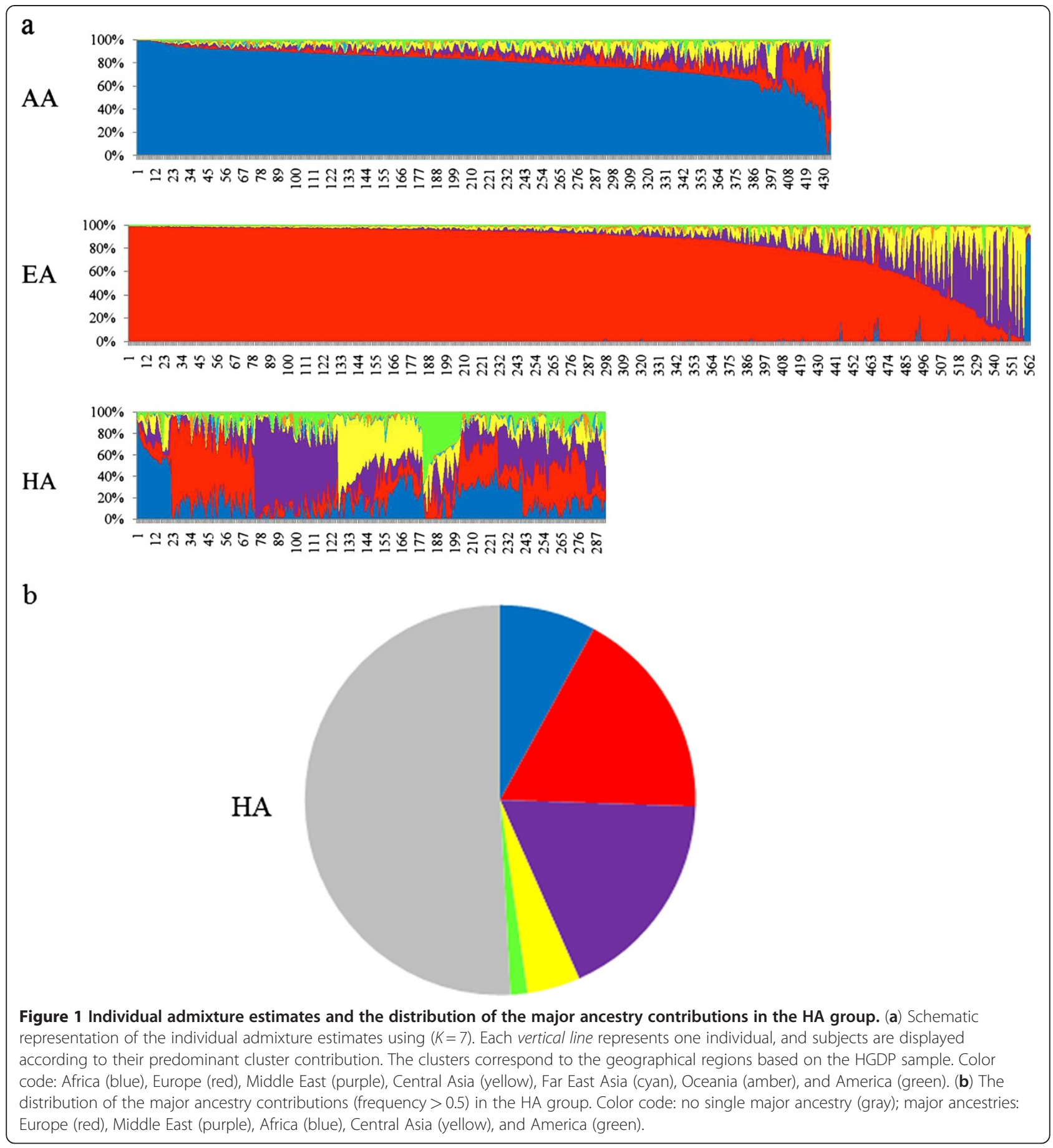

closely related populations such as Europeans [19]. However, to identify potential conflicts between AIMs data and self-identified ethnicity, analysis of the family history data was performed for 34 subjects with a low European ancestry contribution indicated by AIMs analysis $(<0.25)$. No family data were available for six subjects, including one adopted subject. As is shown in Table 2, out of the 18 subjects in which the major contribution indicated by AIMs analysis was from the Middle East, 6 subjects were Jewish (2 of them reported some non-European ancestry), 8 subjects were from Italy, Malta, Greece, or Iran, and 4 have no data available. We have recently showed a high contribution of the Middle East cluster in Israeli non-Ashkenazi Jewish subjects using the same set of AIMs [25]. The one subject, in whom a large Native American contribution was 
Table 1 Self-identification, family history, and ancestry biographical score based on AIMs

\begin{tabular}{|c|c|c|c|c|c|c|c|}
\hline \multirow[t]{3}{*}{ Self-identified } & \multirow[t]{3}{*}{ Family history data } & \multirow[t]{3}{*}{$n$} & \multicolumn{5}{|c|}{ Clusters $(K)^{\mathrm{a}}$} \\
\hline & & & 1 & 2 & 3 & 4 & 5 \\
\hline & & & $\overline{\text { Africa }}$ & $\overline{\text { Europe }}$ & $\overline{\text { Middle East }}$ & $\overline{\text { Central Asia }}$ & America \\
\hline \multicolumn{8}{|c|}{ African Americans } \\
\hline & African American & 179 & 0.83 & 0.05 & 0.05 & 0.05 & 0.01 \\
\hline & Some Caribbean ancestry & 32 & 0.79 & 0.07 & 0.05 & 0.05 & 0.01 \\
\hline & African Caribbean & 40 & 0.82 & 0.05 & 0.05 & 0.05 & $<0.01$ \\
\hline & Some Native American ancestry & 59 & 0.79 & 0.07 & 0.06 & 0.05 & 0.02 \\
\hline & Some European ancestry & 17 & 0.70 & 0.10 & 0.12 & 0.05 & $<0.01$ \\
\hline & Mixed ancestry & 48 & 0.72 & 0.06 & 0.08 & 0.06 & $<0.01$ \\
\hline & New immigrants from Africa & 8 & 0.94 & 0.01 & 0.02 & 0.01 & $<0.01$ \\
\hline & No family data & 52 & 0.74 & 0.09 & 0.07 & 0.08 & $<0.01$ \\
\hline & Total & 435 & 0.80 & 0.07 & 0.06 & 0.05 & 0.01 \\
\hline & (SD) & & $(0.12)$ & $(0.08)$ & $(0.07)$ & $(0.05)$ & $(0.01)$ \\
\hline \multicolumn{8}{|c|}{ Hispanic Americans } \\
\hline & Puerto Rican & 181 & 0.18 & 0.27 & 0.30 & 0.14 & 0.07 \\
\hline & Other Caribbean or mixed Caribbean & 35 & 0.35 & 0.27 & 0.20 & 0.11 & 0.04 \\
\hline & Latin American & 22 & 0.20 & 0.20 & 0.19 & 0.17 & 0.19 \\
\hline & Caribbean/Latin American & 6 & 0.09 & 0.27 & 0.31 & 0.16 & 0.13 \\
\hline & Puerto Rican with some European ancestry & 15 & 0.19 & 0.33 & 0.26 & 0.14 & 0.05 \\
\hline & No data & 34 & 0.17 & 0.30 & 0.24 & 0.17 & 0.09 \\
\hline & Total & 293 & 0.20 & 0.27 & 0.27 & 0.14 & 0.08 \\
\hline & (SD) & & $(0.18)$ & $(0.22)$ & $(0.24)$ & $(0.16)$ & $(0.11)$ \\
\hline \multicolumn{8}{|c|}{ European Americans } \\
\hline & Total & 563 & 0.01 & 0.81 & 0.10 & 0.06 & 0.01 \\
\hline & (SD) & & $(0.01)$ & $(0.17)$ & $(0.13)$ & $(0.08)$ & $(0.01)$ \\
\hline
\end{tabular}

${ }^{\mathrm{a}}$ Data for the clusters corresponding to Oceania and Far East Asia are not presented $(<0.02)$. SD standard deviation.

indicated by AIMs analysis, reported some Latin American ancestry. We found no support in the family history for the subjects in whom a major Central Asian $(n=9)$ or African contribution $(n=2)$ was indicated by AIMs.

Table 2 Family ancestry data in European Americans with $<0.25$ European ancestry

\begin{tabular}{|c|c|c|c|}
\hline Major ancestry (AIMs) & $n$ & Family history & $n$ \\
\hline \multirow[t]{4}{*}{ Middle East } & 18 & Jewish & 6 \\
\hline & & Italy, Malta, Greece & 7 \\
\hline & & Iran & 1 \\
\hline & & No data & 4 \\
\hline Mixed Native American/Middle East & 1 & Latin America & 1 \\
\hline \multirow[t]{3}{*}{ Central Asia } & 10 & Adopted & 1 \\
\hline & & Europe & 7 \\
\hline & & No data & 2 \\
\hline \multirow[t]{2}{*}{ Africa } & 4 & Europe & 2 \\
\hline & & No data & 2 \\
\hline Middle East/Central Asia & 1 & Europe & 1 \\
\hline Total & 34 & & 34 \\
\hline
\end{tabular}

Allele frequencies of mu opioid receptor (OPRM1) SNPs in HA

To illustrate a situation of population-specific allele frequencies and their potential effect in admixed populations, allele and genotype frequencies were calculated for two missense polymorphisms (118A > G (rs1799971) and $17 \mathrm{C}>\mathrm{T}(\mathrm{rs} 1799972))$ in the OPRM1 gene that plays an important role in opioid addiction [26]. Data from dbSNP, HapMap, and ALFRED show that the $118 \mathrm{G}$ allele is common in Asians and Amerindians/Native Americans (0.35-0.5), is rare in African and Oceania populations, and occurs in moderate frequencies in European and Mexican populations (0.15-2.0). The $17 \mathrm{C}>\mathrm{T}$ was not genotyped in the HapMap or ALFRED projects, but other studies and unpublished data from our laboratory indicate that it is African-specific $(0.2-0.3)[27,28]$.

Analysis of genotype data from this study sample shows that the $17 \mathrm{~T}$ allele is rare in EA and HA (0.06) and its frequency in the AA group is $23 \%$, in concordance with data from other studies (Table 3). The $118 \mathrm{G}$ allele is rare in the AA group and has a frequency of 
Table 3 Allele frequencies of OPRM1 SNPs

\begin{tabular}{|c|c|c|c|c|}
\hline \multirow[t]{2}{*}{ Self-described } & \multicolumn{2}{|c|}{17 C > T (rs1799972) } & \multicolumn{2}{|c|}{$118 \mathrm{~A}>\mathrm{G}(\mathrm{rs} 1799971)$} \\
\hline & $\mathrm{C}$ & $T$ & $A$ & G \\
\hline$\overline{E A}$ & 0.98 & 0.02 & 0.88 & 0.12 \\
\hline $\mathrm{AA}$ & 0.77 & 0.23 & 0.97 & 0.03 \\
\hline $\mathrm{HA}$ & 0.94 & 0.06 & 0.82 & 0.17 \\
\hline
\end{tabular}

EA vs. HA $p<0.004$.

$12 \%$ in the EA group and $17 \%$ in the HA group. AIMs data demonstrate that all the carriers of the $118 \mathrm{G}$ allele have some European, Asian, and/or Native American contribution that could explain its origin. The frequencies of the $17 \mathrm{~T}$ and $118 \mathrm{G}$ alleles and their related genotypes in the HA sample were significantly higher than those of European Americans (17\% vs. $12 \%$, and 6\% vs. $2 \%$, respectively, $p<0.004$ for chi-squared test) (Table 3 ). This difference can be explained by the contribution of African and Asian ancestries. Since the contributions of different ancestries vary between different HA samples, the frequencies of the $118 \mathrm{G}$ and $17 \mathrm{~T}$ alleles found in this sample may not represent the frequency in other HA samples.

\section{Discussion}

In this study, we have used a panel of 168 AIMs to estimate the ancestry composition of a multi-ethnic US sample collected for studies of drug addictions in New York City and Las Vegas. We compared this information to self-identified ethnicity and family history data. This comparison revealed high concordance in the major ancestry between self-identified ethnicity and AIMs analysis in African Americans and European Americans in agreement with other studies [10,29-31]. However, selfidentified ethnicity and family history data could not predict the degree of admixture that may have an effect on allele frequencies.

This study reiterates the complexity of the 'Hispanic/ Latino' term. Our results are compatible with studies indicating a relatively high European contribution $(>50 \%)$ in subgroups of this population [5,7-9,12-14]. The study emphasizes the importance of AIMs data in genetic studies of HA since the self-identified ethnicity and family history may not reveal the complex ancestry contributions of this group. A special scrutiny has to be used in casecontrol association studies in this population, and AIMs data should be used to correct for potential population stratification.

The major Hispanic subgroup in this study was Puerto Rican, a population that currently represents approximately $1.5 \%$ of the US population. The pattern of ancestral proportions may have clinical significance for specific diseases when a specific ancestry may have a protective effect based on alleles with higher frequency in this population. For example, a recent study of endstage kidney disease in Hispanics from New York City reported an approximately 30\% African contribution and a very small Native American contribution [9] emphasizing the difference between 'Mexican Hispanics' and 'Caribbean Hispanics.' The sample in the current study was collected in Las Vegas and New York City and has a small, unrepresentative proportion of Hispanics of Mexican origin; conversely, studies with a mix HA from the East, the South West, and the West coasts of the USA are expected to have even larger level of admixture.

This study confirmed the finding of other studies showing a highly diverse proportion of European ancestry in self-identified AAs (7-21\%) [9,22,23,30,32,33]. This diversity can be explained in part by the historical 'one-drop rule' (which classified individuals with any level of African ancestry as 'African Americans'). It is clear that for the AA population, self-identified ethnicity is not sufficient to estimate the admixture level and a random AA sample may differ in admixture level from another sample, to an extent that will affect allele frequencies. The average of $7 \%$ of European admixture in this sample is compatible with some studies [22-24,33] but is lower than other studies $[30,32,34,35]$. This difference may be explained in part by the various numbers of defined clusters used in the different studies. Our STRUCTURE analysis was based on seven clusters, and the European cluster obtained in studies based on small number of clusters is most probably represented in our study by two clusters: Europe and Middle East. These clusters were found to be relatively close (population differentiation index $F_{\mathrm{st}}=0.005$ ) [36] and the Middle East cluster was shown to form a gradient across Europe [37]. Including the Middle East cluster in the total European contribution would result in a $13 \%$ contribution that is closer to the estimate by other studies. The difference between our estimates of ancestral proportions and other studies may also reflect recruitment from different US regions and the use of a different set of AIMs.

Our finding of a very low Native American contribution in this AA sample, based on AIMs analysis, is compatible with other studies $[9,22,32]$ and may represent a conflict with some of the reported family history. It is also possible that this sample does not represent other AA groups in the USA. It most likely does not reflect a limitation in the AIMs set or the analysis since this cluster was clearly detected in HA.

In this study, we have shown the effect of admixture on allele frequencies of two SNPs in the $m u$ opioid receptor gene, OPRM1 (118A $>\mathrm{G}$ and $17 \mathrm{C}>\mathrm{T})$. The significantly higher frequency of the $118 \mathrm{G}$ allele in this small random HA sample compared with the EA sample probably reflects the contribution of Asian and Native American ancestries. Similarly, the significantly higher 
frequency of the $17 \mathrm{~T}$ allele in the HA sample compared with the EA sample most probably reflects the contribution of African ancestry. This study reiterates the importance of AIMs in defining ancestry, especially in admixed populations and emphasizes the concept that Hispanic Americans is not a valid category in genetic research.

This study provides support for the robustness of this set of AIMs, as our results corroborate the results of other studies using this set [18,22-24]. The study demonstrates that computation of ethnic factor scores 'anchored' against worldwide genetic diversity $(\mathrm{CEPH}$ reference populations) yields a stable factor structure, allows comparisons between different datasets, and may permit combining data from different studies. This set of AIMs is especially useful in situations where large-scale genotyping is not available.

There are several limitations to this study: first, our sample does not represent the general US population, as it was derived from only two main locales (Las Vegas and New York City), with unrepresentative low proportion of Mexican Americans. Second, the specific AIMs used in this study were selected based on HapMap data (release \#16c.1, 2005) [19] and as such are limited to allele frequency data from small samples of three main original HapMap populations (Northern and Western Europe $(\mathrm{CEPH})$, Nigeria (Yoruba), and Han Chinese (Beijing)) and may not be suited for analysis of certain populations.

Albeit very promising, great care must be used in research of this kind to avoid misleading interpretations. Genetic ancestry estimates could help the dismissal of the concept of race, but may also support the notion of distinct human biological subgroups that may increase stigmatization and discrimination $[38,39]$. There is growing evidence that major health differences between populations involve gene-environment interaction, and, as such, their understanding will need not only genetic tools but also social/cultural information [22]

\section{Additional files}

Additional file 1: Table S1. List of AIMs.

\section{Competing interests}

The authors declare that they have no competing interests.

\section{Acknowledgments}

We thank all the clinical staff including John Rotrosen, Paul Casadonte (VA New York Harbor Healthcare System), Shirley Linzy (The Adelson Clinic, LV), Lisa Borg, Brenda Ray, Elizabeth Ducat, and Dorothy Melia (The Rockefeller University) for patient recruitment and ascertainment; David Goldman and the Laboratory of Neurogenetics (NIAAA) for assistance with STRUCTURE analysis; Matthew Randesi, Connie Zhao, and Bin Zhang for technical assistance; and Susan Russo for proofreading the manuscript. This work was supported by the National Institutes of Health - National Institute of Drug Addiction [P60-05130 to MJK] and the Adelson Medical Research

Foundation.

\section{Author details}

${ }^{1}$ The Laboratory of the Biology of Addictive Diseases, The Rockefeller University, New York NY10065, USA. 2Laboratory of Neurogenetics, National Institute on Alcohol Abuse and Alcoholism, Bethesda, MD 20892, USA. ${ }^{3}$ The Dr. Miriam and Sheldon G. Adelson Clinic for Drug Abuse Treatment and Research, Las Vegas, NV 89169, USA.

\section{Authors' contributions}

OL designed the study, carried out the genetic studies, performed data analysis and interpretation, and wrote and revised the manuscript. OA performed data analysis and interpretation. PHS performed STRUCTURE analysis. MA supervised subject recruitment, and ascertainment and acquisition of ancestry data of the LV sample. MJK supervised the overall subject recruitment, ascertainment and acquisition of ancestry data, and critically reviewed the manuscript. All authors read and approved the final manuscript.

Received: 1 September 2011 Accepted: 5 July 2012

Published: 5 July 2012

\section{References}

1. Rosenberg NA, Pritchard JK, Weber JL, Cann HM, Kidd KK, Zhivotovsky LA, Feldman MW: Genetic structure of human populations. Science 2002, 298:2381-2385.

2. Rosenberg NA, Huang L, Jewett EM, Szpiech ZA, Jankovic I, Boehnke M: Genome-wide association studies in diverse populations. Nat Rev Genet 2010, 11:356-366.

3. Tian C, Gregersen PK, Seldin MF: Accounting for ancestry: population substructure and genome-wide association studies. Hum Mol Genet 2008, 17:R143-R150.

4. Cardon LR, Palmer LJ: Population stratification and spurious allelic association. Lancet 2003, 361:598-604.

5. Peralta CA, Li Y, Wassel C, Choudhry S, Palmas W, Seldin MF, Risch N, Siscovick D, Arnett D, Psaty B, Shlipak MG: Differences in albuminuria between Hispanics and whites: an evaluation by genetic ancestry and country of origin: the multi-ethnic study of atherosclerosis. Circ Cardiovasc Genet 2010, 3:240-247.

6. Ruano G, Duconge J, Windemuth A, Cadilla CL, Kocherla M, Villagra D, Renta J, Holford T, Santiago-Borrero PJ: Physiogenomic analysis of the Puerto Rican population. Pharmacogenomics 2009, 10:565-577.

7. Bonilla C, Shriver MD, Parra EJ, Jones A, Fernández JR: Ancestral proportions and their association with skin pigmentation and bone mineral density in Puerto Rican women from New York city. Hum Genet 2004, 115:57-68.

8. Bryc K, Velez C, Karafet T, Moreno-Estrada A, Reynolds A, Auton A, Hammer $\mathrm{M}$, Bustamante $\mathrm{CD}$, Ostrer $\mathrm{H}$ : Colloquium paper: genome-wide patterns of population structure and admixture among Hispanic/Latino populations. Proc Natl Acad Sci USA 2010, 107(Suppl 2):8954-8961.

9. Behar DM, Rosset S, Tzur S, Selig S, Yudkovsky G, Bercovici S, Kopp JV, Winkler CA, Nelson GW, Wasser WG, Skorecki K: African ancestry allelic variation at the MYH9 gene contributes to increased susceptibility to non-diabetic end-stage kidney disease in Hispanic Americans. Hum Mol Genet 2010, 19:1816-1827.

10. Divers J, Redden DT, Rice KM, Vaughan LK, Padilla MA, Allison DB, Bluemke DA, Young HJ, Arnett DK: Comparing self-reported ethnicity to genetic background measures in the context of the Multi-Ethnic Study of Atherosclerosis (MESA). BMC Genet 2011, 12:28.

11. Wang S, Ray N, Rojas W, Parra MV, Bedoya G, Gallo C, Poletti G, Mazzotti G, Hill K, Hurtado AM, Camrena B, Nicolini H, Klitz W, Barrantes R, Molina JA Freimer NB, Bortolini MC, Salzano FM, Petzl-Erler ML, Tsuneto LT, Dipierri JE, Alfaro EL, Bailliet G, Bianchi NO, Llop E, Rothhammer F, Excoffier L, RuizLinares A: Geographic patterns of genome admixture in Latin American Mestizos. PLoS Genet 2008, 4:e1000037.

12. Choudhry S, Burchard EG, Borrell LN, Tang H, Gomez I, Naqvi M, Nazario S, Torres A, Casal J, Martinez-Cruzado JC, Ziv E, Avila PC, Rodriguez-Cintron W, Risch NJ: Ancestry-environment interactions and asthma risk among Puerto Ricans. Am J Respir Crit Care Med 2006, 174:1088-1093.

13. Choudhry S, Coyle NE, Tang H, Salari K, Lind D, Clark SL, Tsai HJ, Naqvi M, Phong A, Ung N, Matallana H, Avila PC, Casal J, Torres A, Nazario S, Castro R, Battle NC, Perez-Stable EJ, Kwok PY, Sheppard D, Shriver MD, Rodriguez- 
Cintron W, Risch N, Ziv E, Burchard EG: Population stratification confounds genetic association studies among Latinos. Hum Genet 2006, 118:652-664.

14. Via M, Gignoux CR, Roth LA, Fejerman L, Galanter J, Choudhry S, ToroLabrador G, Viera-Vera J, Oleksyk TK, Beckman K, Ziv E, Risch N, Burchard EG, Martínez-Cruzado JC: History shaped the geographic distribution of genomic admixture on the island of Puerto Rico. PLoS One 2011, 6:e16513.

15. Levran O, Londono D, O'Hara K, Randesi M, Rotrosen J, Casadonte P, Linzy S, Ott J, Adelson M, Kreek MJ: Heroin addiction in African Americans: a hypothesis-driven association study. Genes Brain Behav 2009, 8:531-540.

16. Levran O, Londono D, O'Hara K, Nielsen DA, Peles E, Rotrosen J, Casadonte $P$, Linzy S, Randesi M, Ott J, Adelson M, Kreek MJ: Genetic susceptibility to heroin addiction: a candidate gene association study. Genes Brain Behav 2008, 7:720-729.

17. Ray B, Jackson C, Ducat E, Ho A, Hamon S, Kreek MJ: Effect of ethnicity, gender and drug use history on achieving high rates of affirmative informed consent for genetics research: impact of sharing with a national repository. J Med Ethics 2011, 37:374-379.

18. Hodgkinson CA, Yuan Q, Xu K, Shen PH, Heinz E, Lobos EA, Binder EB, Cubells J, Ehlers CL, Gelernter J, Mann J, Riley B, Roy A, Tabakoff B, Todd RD, Zhou Z, Goldman D: Addictions biology: haplotype-based analysis for 130 candidate genes on a single array. Alcohol Alcohol 2008, 43:505-515.

19. Enoch MA, Shen PH, Xu K, Hodgkinson C, Goldman D: Using ancestryinformative markers to define populations and detect population stratification. J Psychopharmacol 2006, 20:19-26.

20. Pritchard JK, Stephens M, Donnelly P: Inference of population structure using multilocus genotype data. Genetics 2000, 155:945-959.

21. Cann HM, de Toma C, Cazes L, Legrand MF, Morel V, Piouffre L, Bodmer J, Bodmer WF, Bonne-Tamir B, Cambon-Thomsen A, Chen Z, Chu J, Carcassi C, Contu L, Du R, Excoffier L, Ferrara GB, Friedlaender JS, Groot H, Gurwitz D, Jenkins T, Herrera RJ, Huang X, Kidd J, Kidd KK, Langaney A, Lin AA, Mehdi SQ, Parham P, Piazza A, et al: A human genome diversity cell line panel. Science 2002, 296:261-262

22. Ducci F, Roy A, Shen PH, Yuan Q, Yuan NP, Hodgkinson CA, Goldman LR, Goldman D: Association of substance use disorders with childhood trauma but not African genetic heritage in an African American cohort. Am J Psychiatry 2009, 166:1031-1040.

23. Liu J, Zhou Z, Hodgkinson CA, Yuan Q, Shen PH, Mulligan CJ, Wang A, Gray RR, Roy A, Virkkunen M, Goldman D, Enoch MA: Haplotype-based study of the association of alcohol-metabolizing genes with alcohol dependence in four independent populations. Alcohol Clin Exp Res 2011, 35:304-316.

24. Enoch MA, Gorodetsky E, Hodgkinson C, Roy A, Goldman D: Functional genetic variants that increase synaptic serotonin and 5-HT3 receptor sensitivity predict alcohol and drug dependence. Mol Psychiatry 2011, 16:1139-1146.

25. Levran O, Peles E, Hamon S, Randesi M, Adelson M, Kreek MJ: CYP2B6 SNPs are associated with methadone dose required for effective treatment of opioid addiction. Addict Biol 2011, doi:10.1111/j.1369-1600.2011.00349.x.

26. Kreek MJ, Bart G, Lilly C, LaForge KS, Nielsen DA: Pharmacogenetics and human molecular genetics of opiate and cocaine addictions and their treatments. Pharmacol Rev 2005, 57:1-26.

27. Crystal HA, Hamon S, Randesi M, Cook J, Anastos K, Lazar J, Liu C, Pearce L, Golub E, Valcour V, Weber KM, Holman S, Ho A, Kreek MJ: A C17T polymorphism in the mu opiate receptor is associated with quantitative measures of drug use in African American women. Addict Biol 2012, 17:181-191.

28. Gelernter J, Kranzler H, Cubells J: Genetics of two mu opioid receptor gene (OPRM1) exon I polymorphisms: population studies, and allele frequencies in alcohol- and drug-dependent subjects. Mol Psychiatry 1999, 4:476-483.

29. Dumitrescu L, Ritchie MD, Brown-Gentry K, Pulley JM, Basford M, Denny JC, Oksenberg JR, Roden DM, Haines JL, Crawford DC: Assessing the accuracy of observer-reported ancestry in a biorepository linked to electronic medical records. Genet Med 2010, 12:648-650

30. Yaeger R, Avila-Bront A, Abdul K, Nolan PC, Grann VR, Birchette MG, Choudhry S, Burcahrd EG, Beckman KB, Gorroochurn P, Ziv E, Consedine NS, Joe AK: Comparing genetic ancestry and self-described race in african americans born in the United States and in Africa. Cancer Epidemiol Biomarkers Prev 2008, 17:1329-1338.

31. Lee $Y L$, Teitelbaum S, Wolff MS, Wetmur JG, Chen J: Comparing genetic ancestry and self-reported race/ethnicity in a multiethnic population in New York City. J Genet 2010, 89:417-423.
32. Reiner AP, Ziv E, Lind DL, Nievergelt CM, Schork NJ, Cummings SR, Phong A, Burchard EG, Harris TB, Psaty BM, Kwok PY: Population structure, admixture, and aging-related phenotypes in African American adults: the Cardiovascular Health Study. Am J Hum Genet 2005, 76:463-477.

33. Bensen JT, Xu Z, Smith GJ, Mohler JL, Fontham ET, Taylor JA: Genetic polymorphism and prostate cancer aggressiveness: a case-only study of 1,536 GWAS and candidate SNPs in African-Americans and EuropeanAmericans. Prostate 2012. doi:10.1002/pros.22532.

34. Fejerman L, Haiman CA, Reich D, Tandon A, Deo RC, John EM, Ingles SA, Ambrosone CB, Bovbjerg DH, Jandorf LH, Davis W, Ciupak G, Whittemore AS, Press MF, Ursin G, Bernstein L, Huntsman S, Henderson BE, Ziv E, Freedman ML: An admixture scan in 1,484 African American women with breast cancer. Cancer Epidemiol Biomarkers Prev 2009, 18:3110-3117.

35. Murray T, Beaty TH, Mathias RA, Rafaels N, Grant AV, Faruque MU, Watson HR, Ruczinski I, Dunston GM, Barnes KC: African and non-African admixture components in African Americans and an African Caribbean population. Genet Epidemiol 2010, 34:561-568.

36. Tian C, Kosoy R, Nassir R, Lee A, Villoslada P, Klareskog L, Hammarström L, Garchon HJ, Pulver AE, Ransom M, Gregersen PK, Seldin MF: European population genetic substructure: further definition of ancestry informative markers for distinguishing among diverse European ethnic groups. Mol Med 2009, 15:371-383.

37. Kidd JR, Friedlaender FR, Speed WC, Pakstis AJ, De La Vega FM, Kidd KK: Analyses of a set of 128 ancestry informative single-nucleotide polymorphisms in a global set of 119 population samples. Investig Genet 2011, 2:1.

38. Royal CD, Novembre J, Fullerton SM, Goldstein DB, Long JC, Bamshad MJ, Clark AG: Inferring genetic ancestry: opportunities, challenges, and implications. Am J Hum Genet 2010, 86:661-673.

39. Caulfield T, Fullerton SM, Ali-Khan SE, Arbour L, Burchard EG, Cooper RS, Hardy BJ, Harry S, Hyde-Lay R, Kahn J, Kittles R, Koenig BA, Lee SSJ, Malinowski M, Ravitsky V, Sankar P, Scherer SW, Séguin B, Shickle D, SuarezKurtz G, Daar AS: Race and ancestry in biomedical research: exploring the challenges. Genome Med 2009, 1:8.

doi:10.1186/1479-7364-6-2

Cite this article as: Levran et al:: Estimating ancestral proportions in a multi-ethnic US sample: implications for studies of admixed populations. Human Genomics 2012 6:2.

\section{Submit your next manuscript to BioMed Central and take full advantage of:}

- Convenient online submission

- Thorough peer review

- No space constraints or color figure charges

- Immediate publication on acceptance

- Inclusion in PubMed, CAS, Scopus and Google Scholar

- Research which is freely available for redistribution 